\title{
O DESENHO DO MEU CAMINHO: \\ AUTOENTREVISTA COM O DESENHISTA LUIZ FERNANDO GOMES
}

\author{
THE DRAWING ON MY WAY: \\ SELF-INTERVIEW WITH DE BOOKS ILLUSTRATOR LUIZ FERNANDO GOMES \\ EL DIBUJO EN MI CAMINO: \\ AUTO ENTREVISTA CON EL DISEÑADOR LUIZ FERNAND GOMES
}

Luiz Fernando Gomes ${ }^{1}$

https://doi.org/10.47820/recima21.v2i10.894

\begin{abstract}
O presente texto é uma entrevista feita consigo mesmo, (linguista e ilustrador Luiz Fernando Gomes) motivada pelo lançamento em dezembro de 2020, do livro Causos do Leôncio e outros causos, de autoria de Benedicto Cleto, em que atuou como ilustrador. Trata-se, portanto, de uma "autoentrevista" com perguntas de sua própria lavra, baseadas no livro Traço e Prosa (Cosac Naify, 20212) e numa Roda de Conversa com alunos do curso de Letras da Universidade de Sorocaba, disciplina Literaturas Infantil e Juvenil. Aqui, o autor explica seu processo criativo considerando também seus estudos linguísticos sobre as relações verbo-visuais.
\end{abstract}

\section{Fale um pouco sobre como surgiu a ideia da autoentrevista}

$\mathrm{Li}$, recentemente, o livro Traço e Prosa que traz entrevistas com ilustradores de livros infantis, feitas por Odilon Moraes, Rona Hanning e Maurício Paraguassu (Cosac Naify, 2012) e me surpreendi com as histórias reveladas pelos artistas entrevistados ao perceber que pareciam a minha própria história; era como se eu tivesse sido entrevistado e fosse um pouco a soma de todos eles e, paradoxalmente, a subtração, posto que minha história é bem menos realizadora.

\section{Você trabalha com imagens em sua atividade como linguista, não é?}

Sim, na verdade, a partir de meados da década de 1990, as linguagens visual, sonora, espacial e gestual começaram a fazer parte dos estudos linguísticos e eu, naturalmente, passei a estudar uma "gramática da linguagem visual". Pesquisei e orientei trabalhos acadêmicos, e publiquei estudos sobre as relações entre texto e imagem em suas várias manifestações, já que ambos caminham juntos na grande maioria das vezes.

\section{Qual outra motivação para realizar essa autoentrevista?}

A motivação para a redação dessas reflexões é o lançamento do meu livro Causos do Leôncio e outros causos, que é uma coletânea de escritos publicados pelo folclorista Benedicto Cleto (Benecleto) em jornal sorocabano nos anos 1980, que foi organizada e ilustrada por mim. Com esse livro, que foi publicado pela Academia Sorocabana de Letras, eu pretendia mostrar

1 Docente da Faculdade de Letras da Universidade Federal de Alagoas, campus Maceió e do Programa de Mestrado Profissional- PROFLETRAS- em Doutor em Linguística Aplicada, área Linguagem e Tecnologias, Educação. Membro do grupo de pesquisa "Observo- Observatório da Linguagem". ORCID id: https://orcid.org/0000-0002-6302-0071 


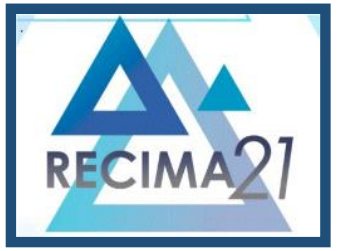

\section{RECIMA21 - REVISTA CIENTÍFICA MULTIDISCIPLINAR ISSN 2675-6218}

meus trabalhos como ilustrador, posto que minhas publicações anteriores eram, em sua maioria, da área da Linguística Aplicada. Pensei, então, em escrever um pouco sobre meus trabalhos como ilustrador e suas interfaces com os estudos linguísticos sobre as relações entre texto e imagem.

Resolvi iniciar fazendo um breve relato sobre minha ligação com o desenho, como se tivesse sido entrevistado para o livro Traço e Prosa. Aproveitei e inseri algumas perguntas feitas numa live pelos alunos do Curso de Letras da Universidade de Sorocabai, em 2021 para enriquecer a "autoentrevista". Curiosamente, a cada pergunta e a cada lembrança que um episódio ou fato que me vinha à lembrança, vários outros me ocorreriam e eu peço desculpas, pois fui me alongando mais do que certamente o faria numa entrevista real, enquanto ia me dando conta da relação siamesa entre mim e o desenho.

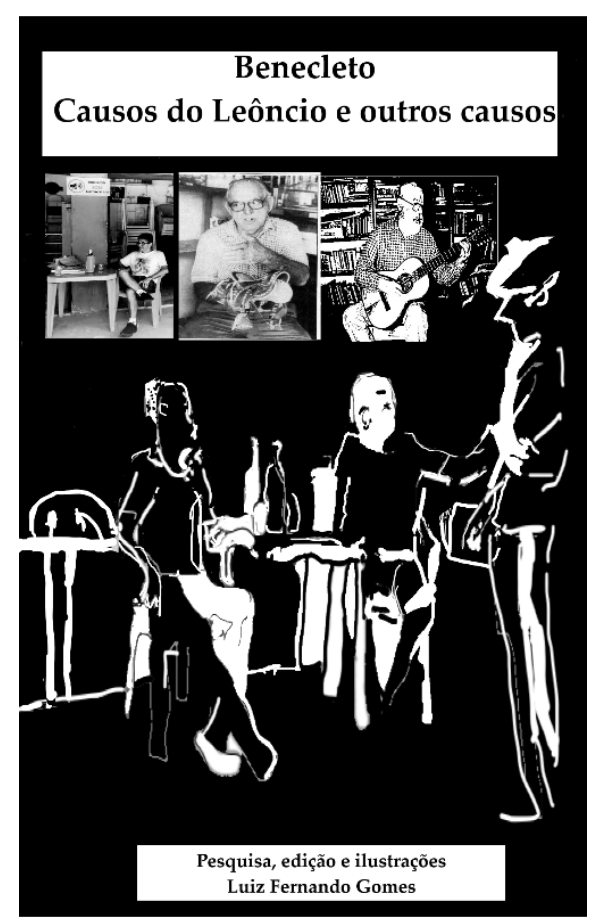

Figura 1- Capa do livro Causos do Leôncio e outros causos

Sem premeditação, de forma natural, o relato foi seguindo uma ordem cronológica, quase como se fosse num divã. Minhas gostosas memórias foram vindas à tona e, de certo modo, dando algum sentido à minha vida.

\section{Você segue aquele clichê de gostar de desenhar desde criança?}

$\mathrm{Na}$ verdade, creio que não. (risos) Mas, os desenhos, as imagens sempre me chamavam muito a atenção.

Minha ligação com o desenho é uma das coisas de que mais tenho certeza sobre meu passado. Desde muito pequeno gostava de um livro com desenhos de pássaros, da ilustração de uma história da Lessie, em que ela salva um cavalo cuja pata ficara prese nos trilhos de uma ferrovia, da capa do disco da Chapeuzinho Vermelho, que eu ouvia sem parar e dos animaizinhos da capa de um disco de cantigas de rodas. Lembro-me das cores e dos detalhes. Eu não sabia ler ainda.

$\mathrm{Na}$ escola primária, era meu costume e de meu amigo Marcos Pezato, a cada novo caderno que começávamos, encapávamos com papel de seda vermelho ou verde, dependendo da série em que estávamos, e o levávamos para uma vizinha chamada Preta, que, aliás, era 


\section{RECIMA21 - REVISTA CIENTÍFICA MULTIDISCIPLINAR ISSN 2675-6218}

branca, para ela fazer um lindo desenho na primeira folha, bem caprichado. Isso lá nos idos de 1966.

Lembro-me de que, certa vez, a professora pediu para fazermos uma pesquisa, em casa, sobe flores e frutos e mostrar o processo reprodutivo deles. Uma colega de classe tinha um irmão que era desenhista e trouxe uns desenhos lindos a carvão e esfuminho numa cartolina branca. Fiquei encantado.

As recordações sobre meu interesse pelo traço, pela cor e pelo desenho se entrecruzam dentro e fora da escola. O material escolar e as tarefas de classe e o "dever de casa" foram importantes para meu contato com itens específicos para desenhar e colorir. No início eu desenhava no papel do pão que embrulhava as "bengalas" que minha mãe trazia da padaria Real. Meu pai comprou para minha irmã, Silvia, que entrara primeiro na escola, um DesenhoCopy, caderno com desenhos em folha de seda que passando o lápis, decalcava na folha para ilustrar trabalhos escolares. Ela não o usou muito, mas eu copiei até rasgar. Também da minha irmã, usei as famosas, na época, canetas hidrográficas Pelykan, que tinham um pelicano colorido na embalagem. Depois, as Canetinhas Hidrocor, que vinham em caixas de acrílico transparente com 6 e 12 cores. Com elas, fiz mapas do Brasil e do mundo; pintei países, vegetações, climas e rios. Meu amigo Sérgio e eu fazíamos mapas com tanto capricho que a professora nos deu nota baixa, pois pensou que fossem recortes de revista. Meu caderno de geografia era todo desenho e cor. Nessa época, descobri o papel vegetal e a delícia de desenhar e pintar nele.

Tive uma caixa de giz de cera de abelha Albion - me recordo bem da marca, pois voraz leitor de Monteiro Lobato anos mais tarde, associei-a a Oblivion, neologismo que nomeia um lugar fictício criado pelo autor, com base na palavra Oblion. Foi um xodó meu. Usei e guardei tanto que nem sei que fim levou. Certa vez, meu pai trouxe para mim e para meu irmão, uma pequena lousa, que consistia numa folha de plástico sobre um suporte de cera ou algo parecido. Ao desenhar sobre a folha com uma caneta sem tinta, os traços surgiam e podiam ser apagados apenas levantando-a, desgrudando a folha plástica do suporte. Era possível fazer inúmeros desenhos sem tinta e sem borracha.

Meu pai, Valter Gomes, tinha um amigo lá na Rádio PRD-7 onde trabalhava, cujo irmão era desenhista. Ele nos deu desenhos do Popeye e do Pica-Pau feitos em cartões grossos, profissionais mesmo. Então, comecei a assistir aos desenhos do Zé Colmeia, Pernalonga, Super Homem, Super Boy, Johnny Quest e tantos outros, sempre com caderno na mão para ir copiando aos personagens. Usava um pouco do caderno de desenho da escola em que cada folha vinha protegida por uma folha de seda. Não usávamos nem a metade dele nas aulas e eu aproveitava as folhas de seda para copiar desenhos de jornais e ainda fazer papagaios.

A tevê Cultura apesentava aos domingos à noite, em preto e branco, um programa sobra animação onde assisti a uma reportagem que mostrava a equipe do Disney em ação, dando movimento aos personagens nas folhas de acetato. Lembro-me também de uma cena em que os desenhistas, de prancheta na mão, ficavam em torno de grandes caldeirões de um líquido espesso e borbulhante praticando copiar e interpretar em traços, o surgimento de bolhas. Creio que utilizaram esse estudo numa cena de um de seus famosos longa-metragens. Havia ainda, um curso de desenho infantil, cujo professor era autor de um livro que meu pai procurou comprar até em São Paulo para mim, mas nunca achou à venda. Nessa época, meu pai chegou a remeter um desenho do Cebolinha ou da Mônica para um concurso divulgado nesse programa (lembro-me do nome da rua para remeter os desenhos: Carlos Spera. Esse era, se não me engano, o endereço do canal de televisão. O nome Spera ficou na memória, pois me lembra minha espera ansiosa pelo resultado do concurso.) $\mathrm{Na}$ verdade, minha esperança era ser desenhista da equipe do Maurício de Souza. Algo tão distante quanto a Lua, para mim. Claro, já quis ser desenhista de histórias em quadrinhos. Fiz duas ou três histórias: uma baseada num conto de ficção científica, outra num conto de horror e uma baseada num conto húngaro. Não sei por que parei.

Via nas revistas em quadrinho que tanto gostava de ler, propagandas do Instituto Universal Brasileiro oferecendo vários tipos de cursos por correspondência. Recortei o cupom e inscrevi-me no curso de Desenho Publicitário. Era fazer desenhos e enviar ao professor que os avaliava e devolvia comentados e riscados em vermelho. Gostei muito do curso. Guardo até hoje todos os cadernos, agora, já bem amarelados.

\section{O desenho no meu mundo do trabalho}




\section{RECIMA21 - REVISTA CIENTÍFICA MULTIDISCIPLINAR ISSN 2675-6218}

Já na mocidade, com emprego arrumado, comprei tubos de tinta a óleo, telas e comecei a pintar. Tive aulas com o professor Edison, numa loja de tintas na Rua da Penha. Lá pintei bonitas cópias - especialidade do professor. Copiávamos pinturas de uma revista americana e de reproduções do pintor paulista Djalma Urban, cujos temas e técnicas eu admirava muito. Depois do professor Edison, passei a ter aulas com o pintor sorocabano Heitor Beranger. Ele criou o que chamava de seringrafia: colocava tinta numa seringa e com ela fazia desenhos enormes em preto e branco. Eu deixava de jogar futebol (uma paixão) nos sábados à tarde para ir à casa dele, na rua Moreira Cesar, próximo à praça do Fórum Velho. Aliás, ao Fórum íamos ele e eu nos encontrar com um pequeno grupo de pintores sorocabanos. Esse grupo nasceu de umas aulas com modelo vivo, que um pintor da cidade, formado nos Estados Unidos, o Gillbert, ofereceu durante suas férias no Brasil. O grupo não durou mais de 3 ou 4 encontros, mas foi o suficiente para irmos num passeio de domingo cedo, pintar ao ar livre, em Aparecidinha. O historiador Adolfo Frioli e o escritor Valdemar Iglesias Fernandes faziam parte desse grupo heterogêneo. Nessa época eu visitava o museu do Zoológico Quinzinho de Barros, então sob a administração do Frioli, para ver e estudar os quadros que retratavam a cidade; muitos deles do Zezé Correia e do Ettore Marangoni. Emprestei umas fotos amareladas da Sorocaba dos anos 1920 do meu amigo, professor Armando de Oliveira Lima, e pintei alguns óleos. Costumava ir à igreja matriz da cidade para admirar as pinturas do artista ítalo-sorocabano Bruno di Giusti. Certa manhã, larguei a timidez e fui me apresentar ao próprio Bruno em sua casa, na rua Professor Toledo. Fui muito bem recebido por ele, que logo me mostrou vários de seus quadros enquanto falávamos sobre arte e a restauração da pintura da matriz, que ele executava naquela época. Eu queria ser um pintor de temas históricos urbanos. Cheguei a pintar vários quadros do bairro onde morei por mais de duas décadas. Eram paisagens urbanas e rurais ao mesmo tempo, como era o Jardim Simus e arredores. Hoje os locais são praticamente irreconhecíveis.

Fui repórter policial do Jornal Diário de Sorocaba e queria muito fazer parte da página infantil. Minha colega de jornal, Elza, havia criado os personagens Joaninha e Biju. Não participei como desenhista do projeto dela. O máximo que consegui foi vestir-me de Biju e irmos ambos dar uma entrevista na Rádio Vanguarda, à famosa jornalista Zilá Gonzaga. Como trabalhei em outros jornais com freelance nessa época, fiz, timidamente, umas charges para o tabloide esquerdista era o tempo do General Figueiredo - "Sorocaba Urgente", fundado pelos jornalistas Airton Segura e Júlio Cesar Gonçalves e do qual faziam parte Paulo Maria Ferreira Leite, Eurípedes Claiton Campos Rodrigues, Lúcio Cesar Tadeu Pires e Roseli dos Santos Cordeiro. O jornal acumulou enorme dívida e fechou creio que no quarto número.

O jornalista Alcir Guedes, que havia sido editor do Diário de Sorocaba, me convidou, certa vez, para escrever sobre uns temas para um jornal que ele editava. Escrevi vários. Me lembro que um que falava sobre a experiência de quase morte ou de pessoas que apresentam melhora de um quadro grave e que depois, inexplicavelmente, morrem. Eu fiz uma ilustração em preto e branco e ela foi publicada. O jornal também não durou muito.

Desanimado com a vida (financeira) de repórter, fui trabalhar na Fábrica de Aço Paulista. Lá, eu fazia desenhos com café destemperado em três copinhos plásticos; decalcava peças com desenhos e formas técnicas exóticas e, convidado pelo pessoal do Recursos Humanos, que ficou sabendo dos meus dotes, passei a ilustrar cartazes de festas da empresa. Uma estagiária, Márcia, que havia cursado Decoração da Escola Pan-americana de Arte, me aconselhou a estudar lá também. Fiquei sonhando. Um dia, faltei do serviço e fui para a Avenida Angélica obter informações sobre o curso. Logo na entrada vi um quadro que é a capa do disco Criaturas da Noite, do Terço, pintada por um professor da escola. Animado, vi os planos das aulas e me matriculei com paixão. Sentia que havia um lugar para mim no mundo. Voltei para casa emocionado. Foram dois anos excelentes. Aprendi muito e me descobri. Guardo todo o material até hoje. Consegui fazer estágio com o Álvaro Zala, à noite, depois do trabalho. Estava aprendendo a ser arte finalista, nos tempos do pastup com estilete e cola bastão. Também era diagramador. O jornal também não durou quase nada.

Criei personagens para encarte de propaganda em jornal de domingo. Não lembro se foram publicados. Desenhei a logomarca da Agência Século XXI. Ficou bonita. O fotógrafo da agência, Pedro, me deu de presente as fotos do meu casamento. A agência fechou cedo.

Alvoroçado com o desejo de viver de arte pedi demissão da fábrica e fui viver meu sonho durante um ano. Pintava e desenhava de manhã à noite. Nossa casa cheirava a terebintina. Era quadro e desenho para todo lado. Aprendi a preparar e esticar telas. Produzia as de tamanho 


\section{RECIMA21 - REVISTA CIENTÍFICA MULTIDISCIPLINAR ISSN 2675-6218}

padrão e por encomenda também. Com isso, conheci vários pintores da cidade e ganhei algum dinheiro, mas, ao findar o ano, desisti e arrumei emprego em outra fábrica. Lá eu desenhei os reservatórios de álcool, os barracões e as sombras projetadas dos barracões da produção em quadros que lembram os de De Chirico.

\section{Desenhando com maior intensidade, agora}

Entrei e dois anos depois saí do curso de Administração de Empresas e de um curso de desenho técnico e fui estudar Letras na Faculdade Dom Aguirre. Desenhava na faculdade e nas lousas nas primeiras aulas de português, inglês e literatura que ministrei. Meu ateliê e minha prancheta verde passaram a dividir espaço com livros de linguística. Eu gostaria muito mesmo é de ter cursado Belas Artes. Não tive condições. Quase toda a minha formação foi informal e autodidata. Pensando que poderia mudar isso, até pouco tempo, sendo doutor em Linguística Aplicada, sonhava em fazer um pós-doutorado em artes.

Saí para dedicar-me ao ensino e à vida acadêmica e familiar, o que tomou a maior parte do meu tempo. Desenhava e pintava apenas nas férias. Eram 30 dias em julho e 45 dias no recesso de fim de ano de muita intensidade, muitos cadernos de desenho, estudos e pesquisas de técnicas e materiais.

A "febre" pegou. Minha filha, Deise, sempre amou a pintura. Desenhava o tempo todo. Tenho dois quadros que pintei sobre desenhos dela, com quatro ou cinco anos.

Expus, no prédio de esquina da rua Souza Pereira com Álvaro Soares, alguns desenhos que retratavam Sorocaba durante a semana de aniversário da cidade, em 2010, se não me engano. Embora a exposição não tivesse tido nenhuma repercussão, eu fiquei animado e já, com mais de cinquenta anos, passei a frequentar o atelier da artista Fernanda Monteiro que me ensinou muita coisa. Fiz uns trabalhos mais plásticos sob a orientação dela e um deles foi inserido numa mostra coletiva em Sorocaba. Minha mudança repentina para Maceió não permitiu que também essa fase perdurasse.

Em Maceió, extasiado com as paisagens, passei a dedicar-me à prática do urban sketch. Aonde quer que eu vá, estou sempre com meu caderno de desenhos, pinceis, lápis e canetas. Inscrevi-me para uma exposição no Museu Theo Brandão aqui na cidade, com uma série de desenhos e montagens fotográficas chamada "O que dizem os peixes". Soube que só havia dois inscritos. Eu não fui o escolhido. Penso agora em como fazer para expor meus trabalhos. Busco caminhos para publicar meus sketchbooks ou para transpor os desenhos de campo sem perder a espontaneidade deles. Tenho experimentado vários materiais e técnicas, inclusive a xilogravura.

Nesse meio tempo, eu publiquei um livro do poesias, palavrando, poemas inconformados, com capa em guache colorido e com desenhos a nanquim nas páginas internas. Queria mostrar os meus trabalhos. Também fiz a capa de um livro meu de contos, $A$ mão que fazia desaparecer $e$ outras histórias impossíveis, e fui convidado para fazer capas de livros de amigos. Escrevi duas histórias infantis, as quais ilustrei com desenhos e colagens, entre outros trabalhos. Recentemente, tive desenhos meus ilustrando capas de uma revista cientifica de linguística, o que para mim foi muito gosto e simbólico: por caminhos transversos pude unir aquilo que havia separado na mocidade - a arte e a ciência.

As entrevistas que estou tomando como "modelo" nesse meu texto trazem perguntas questionadoras sobre diferenças entre pintura e ilustração, sobre as relações texto e imagem, processo criativo, materiais e técnicas e ao final, apresentam seis ou sete trabalhos de cada entrevistado. Ao ler os comentários dos ilustradores, refleti sobre meu próprio processo criativo e minhas opiniões a respeito de alguns importantes temas, promovendo um certo diálogo com os entrevistados. A questão das conexões entre a pintura e da ilustração, por exemplo. A pintura acadêmica, clássica, por muito tempo produziu ilustrações, alegorias e versões visuais de textos mitológicos e religiosos. Por outro lado, algumas ilustrações são como pinturas: podem mesmo ir para a parede emolduradas. Outra questão são as inúmeras funções das ilustrações nos livros de histórias e nos livros didáticos também. Os ilustradores entrevistados sustentam opiniões diferentes, não havendo um consenso sobre a variada tipologia das relações imagem e texto (e vice-versa). Aliás, essa é uma questão em aberto nos estudos da linguística, da semiótica e do design e do livro infantil.

Pelo que se pode observar, no meu relato, estou, nessa última fase, fechando um círculo e juntando a arte e a ciência, o desenho, a pintura, as cores, os traços e as palavras. 


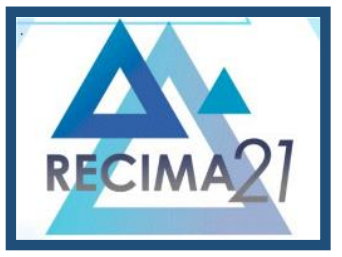

\section{RECIMA21 - REVISTA CIENTÍFICA MULTIDISCIPLINAR ISSN 2675-6218}

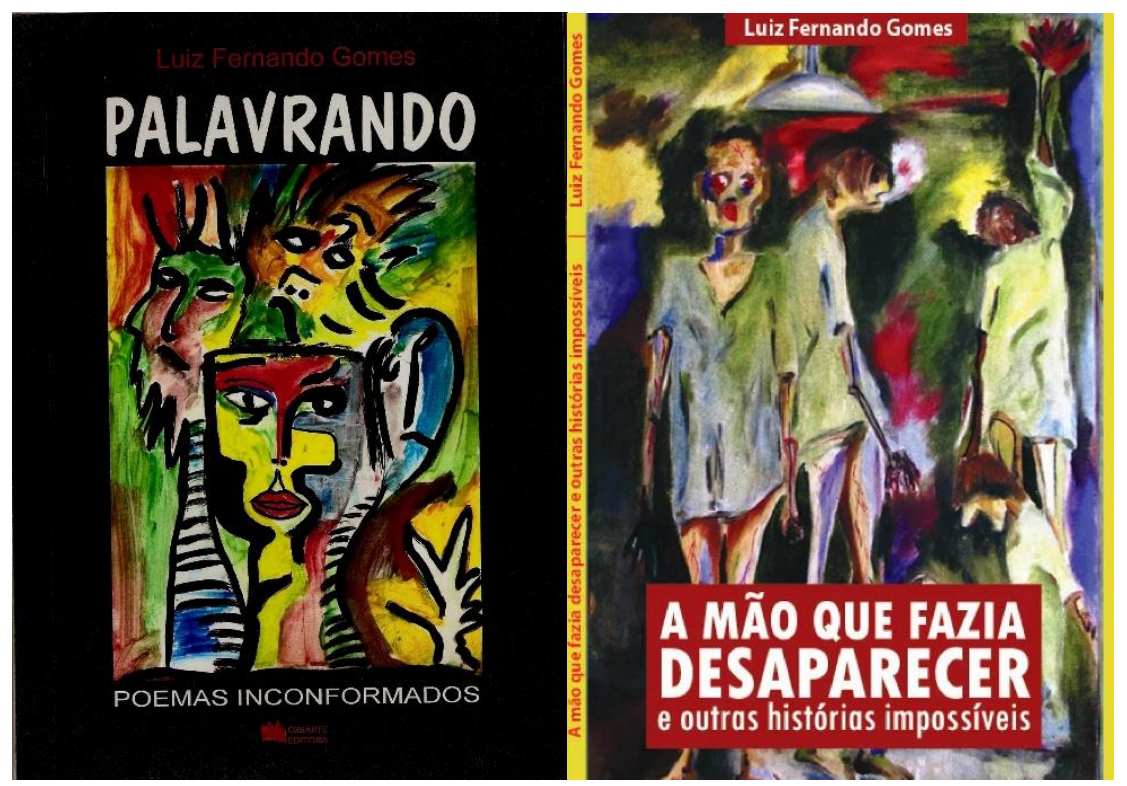

Figura 2- Capas dos livros Palavrando: poesias inconformadas e A mão que fazia desaparecer e outras histórias impossíveis.

\section{Qual é seu processo de criação das ilustrações num livro voltado para crianças ou adolescentes?}

No início, eu não sabia que eu tinha um processo. Por razões práticas, a fim de encaixar meu trabalho informal como ilustrador à minha rotina, acostumei-me a deixar a leitura do texto a ser ilustrado para o momento em que eu tivesse tempo disponível não apenas para ler, mas também para fazer meus primeiros rascunhos. Basicamente, eu vou anotando as palavras ou as cenas importantes no meu caderno de desenho e ao final, essas anotações tornam-se uma espécie de storyboard. Mais difícil de explicar é como eu identifico as palavras-chave, as situações- chave ou qualquer outro elemento textual que gere as imagens virtuais em meu cérebro a serem desenhadas. Falando dentro do campo da arte, eu chamaria isso de intuição, embora linguisticamente, o conceito de palavra-chave seja razoavelmente claro.

Importante ressaltar que eu não leio o texto e vou desenhar tempos depois; tem que ser um trabalho simultâneo, pois a cada nova leitura, possivelmente, novas imagens viriam à minha mente e ficaria cada vez mais difícil escolher alguma entre elas.

Eu acredito que esse meu processo é o mesmo para textos meus ou de outros autores. Talvez a grande diferença seja que dependendo do gênero da história a ser ilustrada, possa demandar uma pesquisa de referências maior, como um conto de fadas, por exemplo, ou uma fábula com animais menos conhecidos, castelos, vestuário etc.

\section{Que tipos de relações tem a ilustração com o texto verbal?}

Essa é uma questão que motivado pesquisas em várias áreas acadêmicas e há muito boas propostas de entendimento do assunto já publicadas. Para o artista, porém, e para mim, no meu processo criativo, a ideia central é de que a imagem deve fazer parte da narrativa de forma intrínseca. Como dizem os criadores do "Nemo: 2 + 2 não são quatro", isto é, os sentidos da parte verbal junto com os da parte visual, formam um sentido outro, individual, que é diferente da simples soma dos sentidos de ambos isoladamente.

\section{Qual a função ou funções da ilustração?}




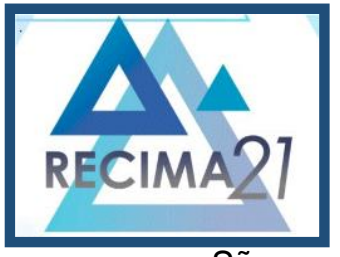

\section{RECIMA21 - REVISTA CIENTÍFICA MULTIDISCIPLINAR ISSN 2675-6218}

São muitas as funções das ilustrações. Menciono algumas, baseando-me numa certa perspectiva teórica, ressalvando que há outras possibilidades: função decorativa, representacional, narrativa, mnemônica, metalinguística. Podem funcionar como pausas e ainda propor um ritmo de leitura. Elas também podem provocar relações de sentido de hipérbole, metáfora, personificação, metonímia e ironia.

As ilustrações também podem relacionar-se de forma coerente ou incoerente semioticamente com suas contrapartes textuais.

Não irei me alongar nessa resposta para não entediar ou confundir o leitor. Mas, deixo o link de um trabalho acadêmico meu publicado para consulta dos interessados. ${ }^{2}$

Uma outra função das ilustrações é promover ou aumentar a venda dos livros. Boas imagens de capa e de páginas internas têm um forte apelo conativo e são utilizadas para sugerir ou indicar já à primeira vista, o público a quem o livro se destina (infantil, adolescente, juvenil etc.) assim como o tipo de obra: aventura, fantasia, terror e por aí vai.

\section{De onde vêm as suas ideias?}

Boa! Está mais para ideias do que para inspiração mesmo. As ideias visuais vêm de todos os meus cadernos de anotações que faço quase diariamente. Além disso, faço também cadernos com recortes de imagens, cores, tipos, fontes, técnicas e materiais: tudo o que me chama a atenção eu recorto, colo, monto, guardo; pego muitas coisas na praia também: rodas de brinquedos enferrujadas, pedaços de madeira com formas curiosas, cacos de telha, coco seco etc. Ah, também faço vários álbuns virtuais de fotos e as organizo em pastas por assunto.

Também gosto muito de usar brinquedos e jogos infantis, desde animais de plástico, até o Pequeno Construtor e o Tandem. Uso origami e maquetes de papelão.

Para a criação das histórias, eu ando sempre anotando palavras, casos acontecidos, frases e ideias que de repente surgem não sei bem de onde. Às vezes, registro em áudio no meu celular e depois transcrevo. Tudo anotado, havendo necessidade, recorro às anotações para desenvolver minhas próprias histórias.

E a memória, ela é fundamental. Não falo da "boa memória" para guardar datas e nomes, por exemplo, falo da memória afetiva, de imagens da infância, da juventude, dos dias atuais. Falo de cenas e cheiros, de cores, de detalhes arquitetônicos e vegetais e, claro, de memórias imaginadas, nunca vistas, mas guardadas lá no fundo, não sabemos como. Sem ela, o que chamamos de criatividade torna-se torturante e quase impossível.

\section{Como é a sua formação como ilustrador?}

Existem ótimos cursos de desenho e de artes; eu mesmo gostaria de ter cursado ao menos um deles, mas, por tanto que li e estudei, esses cursos, embora ótimos, não são um requisito fundamental; a arte não tem um caminho único e nem certeiro. Como eu comentei na pergunta acima, o artista, mesmo que não se reconheça como tal, que não tenha despertado para sua arte (e sua profissão) traz uma certa sensibilidade para a coisa.

Uma parte que tem se tornado cada vez mais importante para um ilustrador é saber trabalhar com mesa digital e com programa de edição de imagens, como o Photoshop, por exemplo. Devido ao processo editorial ter se tornado praticamente todo digital, em algum momento o ilustrador terá que ter seus desenhos no formato de JPG, PNG ou equivalente. Assim, um ilustrador pode desenvolver seu projeto total ou parcialmente na sua prancheta ou na mesa digital. Aliás, poderia até dizer que no meu caso, muitas das coisas que faço no papel, com tinta, pincel, tesoura, cola e até objetos tridimensionais como os origamis poderiam ser feitos diretamente na mesa digital. O material e as técnicas tradicionais de desenho, pintura e colagem, eu os mantenho por gostar muito da sua materialidade, dos volumes, odores e até das chances de errar e ter que apagar ou começar de novo.

\section{Você pensa na produção gráfica também?}

\footnotetext{
${ }^{2}$ Meu artigo Coerência intersemiótica: um estudo aplicado de três modelos de análise das relações imagem-texto está disponível para download gratuito em: $<$ Chapter Details - Blucher Open Access>
} 


\section{RECIMA21 - REVISTA CIENTÍFICA MULTIDISCIPLINAR ISSN 2675-6218}

Sim! Faz parte da criação, pensar nos tamanhos das ilustrações, onde elas serão inseridas, com que finalidade etc. Só por aí já é possível ver a complexidade da tarefa: além de produzir o desenho (ilustração), eu gosto de pensar no seu diálogo com a obra como um todo. Entram nesse cálculo o formato, o tamanho e o peso do livro, o tipo de leitor a quem preferencialmente se destina, os tamanhos e os tipos de fontes, as cores, quantidade de páginas, tipo de papel da capa e das páginas internas, o acabamento e o custo de produção. Mesmo quando temos uma companhia editora que publicará o livro, o autor participa das discussões de cada etapa; quando se produz o livro para depois encaminhar a uma editora, a situação é a mesma, pois é necessário oferecer um produto viável em todos os aspectos.

Do ponto de vista da história e da leitura em si, cada um dos elementos acima - e ainda outros, posto que não incluí os livros digitais, que possuem exigências adicionais - fazem parte da construção de sentidos. O livro é um produto complexo.

Mas há casos em que a ilustração de capa ou de páginas internas são encomendadas pela editora com todas as diretrizes gráficas. Mesmo assim, a escolha, por exemplo, dos tipos a serem usados no título de um livro, por ser a tipologia carregada de expressividade, cabe ao ilustrador usar uma família de tipos já pronta ou criar uma específica, atividade chamada de lettering.

\section{llustrar é interpretar?}

A ilustração traz sempre o ponto de vista do ilustrador e se realiza por meio de sua técnica e de seus materiais, portanto, a ilustração é uma interpretação das ideias do autor do texto e dos materiais utilizados. Alguns dizem até que não há limites para a interpretação, mas eu, particularmente, prefiro manter uma certa "fidelidade" ao que entendo ter sido a ideia do autor, se é que isso é possível.

\section{Pintura, ilustrações, cartoon, quais os limites?}

Quando respondi sobre as funções das imagens num texto, enumerei uma lista não exaustiva de possibilidades. Não há, portanto, algo que não recomende o uso de pinturas entendidas como tradicionais (óleo, acrílica, pastel, guache, aquarela) realizarem qualquer das funções pretendidas pelo ilustrador. Temos, portanto, obras clássicas em capas de livros e capas de livros que se tornaram obras clássicas, que ficam em "exposição" nas prateleiras de bibliotecas particulares e públicas ou que são penduradas nas paredes como ornamento e indicação de bom gosto. Algo semelhante ocorre com cartazes de filmes que se tornaram icônicos. Em meu livro $A$ mão que fazia desaparecer e outras histórias impossíveis, eu utilizei um quadro a óleo na capa e contracapa. Gostei muito do resultado. Livro e quadro não haviam sido feitos um para o outro, mas casaram muito bem.

Um problema que eu me deparei nos desenhos do livro do Causos do Leôncio foi respeitar os limites entre caricatura, cartoon, desenho estilizado (às vezes até a infantilização) ou desenho com esmero acadêmico excessivo. Um peso mais forte dado a qualquer "estilo" conotaria sentidos que provavelmente não se harmonizariam com a proposta da obra e tanto o texto quanto os desenhos perderiam a força.

\section{O que mais marca o seu trabalho como ilustrador?}

Fiz relativamente poucas ilustrações até agora e não creio que tenha criado uma marca identificável, mas eu tenho um estilo, um jeito, um traço que me são característicos. Eles foram sendo desenvolvidos e foram se fixando através de uma extensa, sem que eu fizesse alguma racionalização.

Claro que busquei (e continuo aperfeiçoando) um traço que melhor se adequasse ao meu modo de ver e de desenhar o mundo; o mesmo, posso dizer sobre o uso das cores, dos materiais, dos locais e horários em que me sinto mais disposto para o trabalho criativo.

Espero que um dia eu tenha os traços tão bonitos e característicos de Poty, Aldemir Martins e Carybé! 


\section{RECIMA21 - REVISTA CIENTÍFICA MULTIDISCIPLINAR ISSN 2675-6218}

\section{Para encerrar nossa entrevista, o que você chama de alfabetização visual?}

Também podemos ampliá-la e chamá-la de letramento visual. Em poucas palavras, seria o reconhecimento e o domínio dos códigos verbais e visuais e dos seus modos de expressão e de produção de sentidos, por parte tanto do leitor quanto do produtor de textos verbo-visuais. $\mathrm{O}$ letramento visual é um processo que está ligado à habilidade leitora. Há todo um mundo de informações, de beleza e de sentidos nas imagens que um olhar superficial não consegue ver e que enriquecem a experiência da leitura. Acredito que é papel da escola incluir o letramento visual em seu currículo sob pena de estar formando leitores de uma só linguagem.

\footnotetext{
i Gostaria de agradecer ao prof. Me. Márcio José Pereira de Camargo, pelo convite para participar da Roda de Conversa intitulada "Imagem e Literatura", como parte do programa por ele ministrada: Literaturas Infantil e Juvenil no Curso de Letras da Universidade de Sorocaba, Uniso, ocorrida em 14 de abril de 2021. Estendo meus agradecimentos a todos os alunos e alunas que ativamente participaram do evento.
} 